\title{
EL SENTIDO PERSONAL COMO CO-LUZ INTIMA ORIENTADA AL SENTIDO ORIGINARIO
}

\section{THE PERSONAL HUMAN MEANING AS INNER CO-LIGHT REFERRED TOWARDS THE ORIGINAL MEANING}

\author{
María Victoria Cadavid Claussen ${ }^{1}$ \\ Universidad Católica de Colombia
}

Recibido: 19/11/2016

Aceptado: 21/03/2017

\begin{abstract}
Resumen: La propuesta del sentido personal como co-luz íntima se funda en la Antropología trascendental de L. Polo. El sentido personal como tema se alcanza con el hábito de la sabiduría que Polo denomina carácter de además. Ser además equivale a ser co-luz en tanto que ámbito interior de transparencia cognoscente metódico-temática. La expresión 'co-luz' se refiere al acto de ser personal como co-sentido en apertura íntima sin término trocada en búsqueda aceptante de un sentido superior. La sabiduría en tanto que hábito solidario al co-sentido es intrínseco a la intensidad de la luz transparente temática que alcanza. De ahí la intensidad del co-sentido como sobrar de luz íntima capaz de orientarse al sentido originario así como también de atravesar todo lo inferior.

Palabras clave: Co-sentido personal, intelecto personal, sabiduría, ámbito íntimo luminoso, transparencia, búsqueda aceptante, libertad personal, amardon al, co-existencia, carácter de además, tema-método, esencia humana, límite mental.
\end{abstract}

\begin{abstract}
The proposal of the personal meaning as intimate co-light is based on Polo's Transcendental Anthropology. The personal meaning as them is methologicallly reached by the habit of wisdom that Polo called character of additionally. Being Additionally is equivalent to be co-light in both inner as a method-them or personal knowledge as transparency ambit. Co-light refers to the personal act of being as co-meaning in intimate opening without end changed in accepting search for higher meaning. Meanwhile solidarity habit to the co-meaning wisdom is intrinsic to thematic as a transparent light that

1. (mvcadavid@ucatolica.edu.co) Coordinadora de Investigaciones del Departamento de Humanidades de la Universidad Católica de Colombia. Docente de planta investigadora del Grupo de Investigación Philosophie Personae del mismo departamento. Doctoranda del Departamento de Filosofía de la Universidad de Navarra. Director de tesis: Dr. Juan Fernando Sellés D. Tema: El Sentido Personal desde la Antropología Trascendental de Leonardo Polo.
\end{abstract}


reaches unfinished. Therefore the co-meaning as left over light of inner intensity, is also able to refer towards the original meaning as well as to traverse any lower.

Key words: Personal co-light, personal intellect, wisdom, luminous intimate area, transparency, accepting search, personal freedom, loving-giving, co-existence, character of additionally, them-method, human essence, mental limit.

\section{Introducción}

La antropología trascendental ${ }^{2}$ propuesta por L. Polo presenta un aspecto radical constitutivo del acto de ser humano: el carácter de además. Este trabajo pretende destacar la relevancia del además como núcleo personal de luz de sentido dual, o co-sentido, trocado en dinamismo trascendental como búsqueda aceptante de un tema superior que es Dios. El ser además refiere a una dualidad de luz intelectual por tanto co-luz, que como método noético y tema conforma el acto de ser personal humano $^{3}$. La co-luz metódico-temática abre un ámbito íntimo luminoso que,

2. Polo presenta así su propuesta antropológica: "Para emprender el estudio de la antropología trascendental se precisa ampliar la perspectiva: coexistir es más digno que existir; el ser humano es superior al ser del universo, y los trascendentales personales también son superiores a los metafísicos; bien entendido: sin que esto comporte rivalidad u oposición, ni que haya que optar entre metafísica y antropología. No se trata de una diferencia dialéctica o negativa, sino de una distinción. El ser humano no es la negación del ser del universo; sino, más bien, la ratificación de los llamados trascendentales relativos. La antropología juega a favor de la metafísica, no se opone a ella ni la sustituye". Polo, L., Antropología, I, 34. Sobre la antropología de Polo comenta Sellés: "no significa que su antropología sea 'teología sobrenatural', aunque compatible con ella. No es siquiera 'antropología teológica' en el sentido de una visión del hombre que se pueda enmarcar en la tradición de teólogos cristianos, sino, por así decir, 'antropología filosófica teocéntrica', pues su planteamiento es filosófico, pero ve al ser humano enraizado en el ser divino, pues lo contrario no es propiamente "antropología", sino precisamente el capital reduccionismo antropológico (que inicialmente conlleva la pérdida de sentido personal, y que finalmente termina con la negación del hombre)". SeLLÉs, J.F., "La distinción entre antropología y ética", Studia Poliana, 13 (2011) 126.

3. "El intelecto como acto es un trascendental que se convierte con la libertad; el intelecto humano es la persona. Libertad e intelecto son trascendentales personales". PoLo, L., Antropología, I, 119.

Thémata. Revista de Filosofía Nº56 (2017) pp.: 255-284. 
como intelecto ${ }^{4}$ de nivel trascendental, es además cognoscente y libre ${ }^{5}$ trocado en búsqueda-aceptante del Sentido Originario. También se pretende resaltar aquí el juego dual de la luz solidaria metódica y temática o co-luz de sentido que, por una parte, insiste en ser como dinamismo ascendente luminoso de sentido que se orienta a su tema, y por otra, es co-luz unitiva otorgante que en su descenso ilumina las dualidades inferiores hasta sus manifestaciones esenciales humanas e incluso las naturales.

La dualidad de luz radical metódico-temática del carácter de además o co-sentido tiene dos miembros solidarios. El superior es el tema, sentido personal o transparencia ${ }^{6}$, conformado por la luz íntima ${ }^{7}$ del intellectus ut co-actus ${ }^{8}$ como conocer personal en acto, es decir, un conocer de nivel trascendente superior a la razón. Y el inferior es el método, la luz

4. "El intellectus ut co-actus es la elevación al nivel trascendental de lo que en la tradición se llama intelecto agente. Se suele decir que el intelecto agente no se conoce a sí mismo, sino que es una luz que permite conocer los inteligibles. Según mi propuesta, es el acto radical del que dependen los otros actos intelectuales, los cuales, por ser inferiores a él, no lo conocen de ninguna manera. Sin embargo, en el orden personal, el acto intelectual se convierte con la persona. El intellectus ut co-actus es el núcleo del saber, desde el cual-radicalmente-se ejercen las operaciones y los hábitos; pero él no es estrictamente ninguno de ellos, por ser el acto intelectual superior. Que la persona sea el acto intelectual superior no comporta identidad intelectual, pues la identidad es exclusiva de Dios". Polo, L., Antropología, I, 224.

5. "...es claro que no cabe hablar de libertad transcendental sin la aludida conversión con el intelecto; al margen de ella, la libertad es una noción incoherente o arbitraria”. Polo, L., Antropología, I, 119.

6. "La transparencia no se confunde con la diafanidad del cristal. Lo diáfano es más bien pasivo respecto de la luz que lo atraviesa y, por tanto, carece de lo que hemos llamado intensidad de la transparencia. La intensidad de la transparencia es la luz intelectual por dentro, pues ese dentro es luz". Polo, L., Antropología, I, 197. Sellés explica que en Polo "se trata de un nuevo modo de llamar al entendimiento agente clásico. Polo también lo designa con las expresiones: "entendimiento agente" (Curso de teoría, III, 22) o "núcleo del saber" (Curso de teoría, III, 338; El acceso, 54), "entendimiento coagente", "intelecto personal", "esse hominis" (Curso de teoría, III, 26; "intellectus ut actus", SELLÉs, J.F., "El intelecto agente como acto de ser personal" Logos. Madrid. 45 (2012) 43. Cfr. sobre este tema: GARCíA, J.A., "Discusión del entendimiento coagente", Studia Poliana, 2 (2000) 51-71.

7. "Transparencia equivale a co-acto, es decir, a intimidad". Polo, L., Antropología, I, 197.

8. Respecto del intellectus ut coactus Polo aclara: "En la radicalidad trascendental que es la persona están el amar y el inteligir; no la intelección de la naturaleza, sino el inteligir como persona. El conocimiento de lo inferior depende del intellectus ut coactus a través de la sindéresis, y corre a cargo de las operaciones y los hábitos, de manera que el intellectus ut coactus no se agota en esos niveles". Polo, L., Antropología, I, 167.

Thémata. Revista de Filosofía N56 (2017) pp.: 255-284. 
del hábito innato de la sabiduría ${ }^{9}$, un conocer habitual, que es alcanzar ${ }^{10}$ al núcleo luminoso para dar cuenta de su luz. Esta solidaridad de luz con la luz es de carácter radical, es decir, constitutiva del acto de ser humano como co-luz o co-sentido personal. Por tanto, la dualidad luminosa solidaria es trascendental ${ }^{11}$, distinta de las otras dualidades humanas ${ }^{12}$ no trascendentales con las que Polo explica la naturaleza manifestativa del hombre.

Las dualidades conforman, según Polo, la estructura del ser humano, tanto en el nivel radical como en su nivel manifestativo, e indican la apertura del miembro inferior de la dualidad al miembro superior, que a su vez se abre a otra dualidad superior. Así, por dualidades, se dinamiza el sentido trascendental y se deriva su luz desde el núcleo de luz radical, que es la persona humana, a lo inferior, sus manifestaciones. La dualidad trascendental se refiere, por tanto, a los aspectos constitutivos del acto de ser humano o co-sentido, que están dualizados a su vez con los hábitos

9. Sobre la solidaridad del intellectus ut co-actus y la sabiduría Polo escribe: "El intellectus ut co-actus es la luz penetrada de luz, pues, como tema del hábito de sabiduría, se alcanza según el carácter de además. Este hábito es solidario con su tema porque, de otro modo, la persona quedaría quedando inédita. Pero no se trata de que la persona se conozca reflexivamente, puesto que es co-existencia abierta. El autoconocimiento reflexivo de la persona se excluye porque, si bien el hábito de sabiduría es solidario con su tema, no se confunde con él, ya que el hábito de sabiduría y el intellectus ut co-actus no son un único acto". PoLo, L., Antropología, I, 180.

10. "De esta manera, el tema que alcanza es aún más real que el acto de ser extramental creado, y por eso se ha descrito como co-ser o co-exitir". Polo, L., Antropología, I, 197.

11. Polo afirma el intelecto y la verdad personal como trascendental: “...la intelección humana es trascendental si la verdad se contempla como persona”. Polo, L., Antropología, I, 166-167. También afirma: "Precisamente porque el carácter de además no tiene sentido yuxtapuesto o comparativo, y no se entiende como diferencia sino como distinción, equivale a alcanzar un nuevo sentido del acto de ser con el cual es solidario. Por tanto, posee valor trascendental". Ibid., 164.

12. Sobre las dualidades humanas Polo indica: "Apelaré, ante todo, a una peculiaridad observable en el hombre, a la que, como he indicado conviene llamar dualidad". Polo, L., Antropología, I, 164. Y amplía: "el hombre no es una realidad simple sino, como se puede observar, sumamente compleja, por lo que, con frecuencia, su estudio no se sabe controlar o se afronta de una manera parcial. Dicha complejidad se enciende de acuerdo con el criterio de dualidad. Los aspectos duales del hombre son muy abundantes. Por ejemplo, acto de ser y esencia; cuerpo y alma; voluntad e inteligencia; interioridad y exterioridad; operación objeto; hábito y operación; hábitos innatos y hábitos adquiridos; sociedad e individuo; hombre y mujer". Ibid. En otros términos dice: "Es propio de las dualidades humanas un sentido ascendente o jerárquico. Dicha ascensión se debe a que uno de los dos miembros de cada dualidad es superior a otro, por lo que no se agota en su respecto a ese otro, sino que se abre a una dualidad nueva.". Ibid., 167.

Thémata. Revista de Filosofía N56 (2017) pp.: 255-284. 


\section{El sentido personal como co-luz íntima \\ orientada al sentido originario}

innatos inferiores a él. Por consiguiente, resulta de sumo interés conocer en qué consiste la peculiar dualidad solidaria de co-luz de sentido radical.

\section{La co-luz íntima como carácter de además}

El co-acto personal o co-sentido es la dualidad radical luminosa del hombre como sobrar ${ }^{13}$ trascendental de luz en la luz que no culmina; es, por eso, el carácter de además metódico-temático. La solidaridad de la luz dual metódico temática conforma un ámbito íntimo ${ }^{14}$ de co-luz que sobra, pues es luz intelectual que va a más sin agotarse, es activa y, por tanto libre ${ }^{15}$. El intellectus ut co-actus es transparencia ${ }^{16}$ de sentido radical como tema de la luz metódica de la sabiduría ${ }^{17}$ que lo alcanza. A su vez, el intellectus ut co-actus es luz abierta ${ }^{18}$ para ser alcanzada, siendo a

13. "Así, por ejemplo, cuerpo-alma es una dualidad cuyos miembros no son del mismo rango, pues el alma es superior al cuerpo. Por tanto, el alma no es solo dual respecto del cuerpo, sino que se abre a otra dualidad. Este peculiar rebrotar de las dualidades, es decir, el no agotarse uno de los miembros de cada dualidad en su respecto al otro, indica el carácter sobrante del miembro superior. Y en este sentido es una indicación del carácter de además". Polo, L., Antropología, I, 197. También afirma Polo: "El carácter de además es puro sobrar". Ibid., 197.

14. El co-sentido es sobrar solidario de luz como ámbito interior: "Transparencia equivale a co-acto, es decir a intimidad. Por eso, tanto da decir que el tema es interior al método como que el método es interior al tema; la transparencia no es temática sino metódica, y no es metódica sino es temática; no se reduce, por así decir, a un punto focal. El carácter de además es puro sobrar. No lo sería sin dualidad sin inclusión”. Polo, L., Antropología, I. 197. Por otra parte Polo indica con relación a la solidaridad de tema y método de la co-luz "el tema dentro del método; un dentro atópico porque el método no es un lugar, y porque el tema tira del método, y no es insondable como Identidad Originaria”. Ibid.

15. "En suma, el descubrimiento de la intimidad como apertura interior e inseparable del valor activo, libre, dela co-existencia (...). Si la persona fuese única, la intimidad no sería activa y no existiría. Por consiguiente, e un error aseverar que la persona carece de intimidad. en rigor, la persona humana descubre que interiormente carece de réplica. Ahora bien, como esta carencia no puede ser definitiva, es, por tanto, activa de inmediato". Polo, L., Antropología, I, 205.

16. "La persona, a la que también llamo el núcleo del saber, es luz en la luz, es decir, la transparencia.” Polo, L., Antropología, I, 223.

17. "El carácter de además como método es el hábito de sabiduría el cual es solidario o indisociable con la temática trascendental. Es la tercera dimensión del abandono del límite mental". Polo, L., Antropología, I. 190.

18. "La dualidad del carácter de además no es oclusiva, no comporta determinación. Todo lo contrario: de acuerdo con su dualidad, el carácter de además está, permanentemente abierto... no una oclusión o autodeterminación sino la intensidad de la transparencia". PoLo, L., Antropología, I, 197.

Thémata. Revista de Filosofía Nº56 (2017) pp.: 255-284. 
su vez interior al alcanzarse como método habitual. Se trata de un juego de sentido interior de co-luz metódico-temático inseparable ${ }^{19}$ que no cesa; de ahí su sobrar solidario luminoso.

Por su carácter metódico ${ }^{20}$ la sabiduría como además es luz precaria sin su tema. Por eso la solidaridad del método con la luz transparente temática comporta que el tema tire del método hacia arriba para que no decaiga en su ascender transcendental alejándose del límite mental. Así, el insistir de la luz temática del co-sentido es a la par alejamiento metódico de la fijación, sin término. Fijarse es quedarse en el limite mental ${ }^{21}$, sucumbir al pensamiento objetivo. En cambio, alcanzar el tema significa desaferrarse de la fijación mental operativa para no quedarse en el objeto sino ir a más. Alcanzarse como co-sentido es dar cuenta del tema personal como co-acto de luz dinámico, es decir en conversión radical de los trascendentales antropológicos; es conocerse como co-sentido luminoso, cognoscente, libre y amoroso. Por tanto, ser además insiste en un además luminoso no como proceso gradual, sino como insistencia inagotable de la luz en la luz íntima. Por esto la luz del co-sentido es dinamismo unitivo. Por ser luz de además interior al carácter de además, como luz en la luz, este co-ser luminoso metódico-temático radical es coexistencia interior, es decir, la luz transparente temática atraviesa el método luminoso ${ }^{22}$ en su

19. "Sucede entonces que la índole creada de un acto intelectual no sólo estriba en la potencia que le corresponde, o que de él depende; sino previamente en su interna dualidad entre el cognoscente y su actividad noética, con la temática que ésta alcanza". GARcía, J.A., "El entendimiento humano, según Leonardo Polo", en González, A.L., - Zorroza, I., (eds.), In umbra intelligentiae, Eunsa, Pamplona, 2011, 489.

20. "La aportación poliana, aunque compatible con los descubrimientos de la tradición aristotélico-tomista precedente, es del todo singular; su originalidad nace del valor metódico que otorga a este hábito". SELlÉs, J.F., "El hábito de la sabiduría según Leonardo Polo", Studia Poliana, 3 (2001) 77.

21. El límite mental es punto de partida para la antropología: "que la antropología sea una ampliación transcendental respecto de la metafísica, se justifica por la pluralidad de dimensiones del abandono de lo único. Lo único, estrictamente, no es más que el límite mental". PoLo, L., Antropología, 200. Al respecto Sellés amplía: "El límite mental es la operación cognoscitiva, la presencia que presenta al objeto conocido y se conmensura con él. Según sea el abandono de esa presencia se puede acceder a conocer unos determinados temas reales u otros, pues el método de su abandono tiene cuatro dimensiones". SELLÉs, J.F., "El hábito de sabiduría", cit., 83.

22. "Como se notará, el enfoque que propongo difiere del tomista porque trata de averiguar el valor metódico del hábito de sabiduría para el conocimiento del intelecto personal. Sólo entonces se podrá estudiar de qué manera la sabiduría es cognoscitiva Dei. No se acepta que el hombre sepa que existe al pensar algo, porque esta tesis tiene un sentido reflexivo, y guarda cierta semejanza con la inferencia cartesiana del sum. Con todo, la gran importancia que Tomás de Aquino concede al hábito de sabiduría constituye un punto de referencia obligado para la antropología trascendental”. PoLo, L., Antropología, I, 155.

Thémata. Revista de Filosofía N56 (2017) pp.: 255-284. 
interior para alejarse del límite mental y alcanzar la transparencia de su núcleo de co-sentido a modo de juego de luces que no se separan.

Ser luz interior en la luz es ser co-luz. El núcleo de co-sentido es un dentro atópico ${ }^{23}$ dice Polo, a modo de amplitud íntima de luz dual que insiste en ser, por tanto creatural, no idéntica como la Luz Originaria. No se trata de una ubicación, sino de un ámbito radical de sentido luminoso dual. Es decir, luz temática que atraviesa la luz metódica para tirar de ella hacia arriba, hacia el núcleo de co-sentido personal, insistiendo en la tensión del alejarse del límite del pensamiento objetual para superarlo alcanzándose como persona. El co-sentido como miembro superior de la dualidad de co-luz es luz temática trascendente que busca su réplica y, por tanto, va a más, y, como luz metódica, es el hábito innato de la sabiduría, miembro inferior de la dualidad que da cuenta del co-ser luminoso que es su tema al alcanzarlo. Por eso el límite mental es su punto de partida, la línea que marca el límite entre la esencia extramental y la esencia del hombre, del cual parte la co-luz del además para alcanzarse como co-sentido personal.

En efecto, el co-sentido personal es además del ser extramental sin desconocerlo como ser primero, sino fijando su atención en él para dejarlo ser. El carácter de además se distingue del ser extramental secundarizándose ${ }^{24}$ como otro ser distinto de él. En tanto que co-acto de ser más real que el mismo ser extramental, por no tener que distinguirse de la nada como el ser del universo, el co-sentido es superior al acto de ser metafísico. También la co-luz metódico-temática del co-sentido es además de la esencia extramental, como manifestación física del ser del universo, que está separada de la esencia humana por el límite mental. Este límite, por tanto, marca la distinción de la esencia humana como superior de la esencia extramental. El núcleo de co-luz no alberga así la operación cognoscitiva para no sucumbir en ella como consistencia inamovible de su luz, pues la presencia mental equivale al límite mental ${ }^{25}$. Por eso no fi-

23. "Este es el valor de hábito innato del carácter de además que cabe llamar interno a él, o coexistencia: el tema dentro del método; un dentro atópico porque el método no es un lugar, y porque el tema tira del método, y no es insondable como la Identidad Originaria". PoLo, L., Antropología, I, 197.

24. "Por eso se dijo que la persona es el segundo sentido del acto de ser: se distingue de los primeros principios porque la persona se 'secundariza' radicalmente: coexistencia, intimidad sin réplica, insistencia metódico -temática, transparencia, y no insondabilidad originaria”. Polo, L., Antropología, I, 198.

25. "El tiempo no es un éxtasis en el que aparecen presente, pasado y futuro, porque el presente no es una dimensión más del tiempo sino la instancia desde la que la mente humana lo articula. Hay pasado y futuro porque hay presente, y hay presente en virtud de la presencia, que se identifica con la actividad básica de la inteligencia humana. En otras palabras, el

Thémata. Revista de Filosofía $\mathrm{N}^{\circ} 56$ (2017) pp.: 255-284. 
jarse en el límite mental indica desarraigarse de él, no albergándolo como exsención ${ }^{26}$, sino alejándose de él como luz activa hacia arriba, hacia el co-sentido como tema ${ }^{27}$.

Alcanzar el co-sentido como tema es dar cuenta de ser además como ámbito de co-luz, abierto, activo y luminoso. Este ámbito es apertura íntima en semejanza con el tema que a su vez busca, el ámbito de máxima amplitud ${ }^{28}$ del Sentido Originario. Esa semejanza es creada, pero no derivada sino singular, es decir, el co-sentido personal humano es distinto en dependencia del Sentido Originario divino. De ahí que el co-sentido sea amplitud íntima en tanto que dualidad de luz solidaria de su transparencia temática con el alcanzar metódico de luz. Y que a la vez sea ámbito íntimo activo y cognoscente y por eso dinamismo luminoso de sentido que busca el Sentido Originario.

El ámbito íntimo de co-luz del co-sentido, es ámbito atópico no físico, sino apertura de amplitud íntima de sentido personal que se abre por el insistir de la luz de la trasparencia en la luz de la sabiduría. Con otras palabras, la luz del hábito metódico en la luz del acto de ser transparente y la insistencia mutua luminosa, abre un ámbito que Polo llama coexistencia, pues no se trata de una luz única, sino de co-luz o co-sentido. Así lo describe: "si en el hombre el ser es dual, es decir, si el acto de ser humano

presente no es real fuera de la mente, aunque la tentación de ponerlo en ella, confundiendo lo real con nuestro modo inmediato de conocerlo, acompañe ineludiblemente a la mente humana". Murillo, J.I., "Diálogo y verdad en la antropología trascendental de Leonardo Polo", en: VV. AA., Verdad y diálogo. Actas del Simposio Internacional celebrado en San Petersburgo (29-31-V-2008). San Petersburgo (Rusia): Ediciones de la Academia Ruso-Cristiana de Humanidades, 2008, 379 .

26. "La tercera dimensión del límite mental se desaferra de la exsención presencial, pero no prescinde de ella, por lo que la presencia juega como punto departida de dicho método. De esa manera, el tema que se alcanza es más real que el acto de ser extramental creado, y por esto se ha descrito como co-ser o co-existir”. Polo, L., Antropología, I, 195.

27. "De acuerdo con ello, al acto intelectual humano competen estos tres ejercicios activos: - suscitar y englobar la intelección esencial, es decir, todo cuanto la inteligencia obtiene al activarse (y también encontrar lo que se torna explícito desde esa activación: la esencia causal del universo), pero después, advertir la existencia extramental, es decir, la del creador y la de la otra criatura, la que no es intelectual: la del universo. - y además alcanzarse y buscarse como ser intelectual que es; y referirse como tal al creador". GARCíA, J.A., "El entendimiento humano, según Leonardo Polo", En: González Zorroza (eds.): In umbra intelligentiae. Eunsa, Pamplona (2011), 490-491.

28. "La interioridad del Origen no acaba nunca, y que de acuerdo con su carácter originario no se completa, sino que es una interioridad infinitamente intensa en tanto que idéntica. La intensidad del Origen es inabarcable, es decir, máximamente amplia y, así, tema del intelecto personal humano. En atención a ello sostengo que el carácter de además se incluye atópicamente en el ámbito de la máxima amplitud”. Polo, L., Antropología I, 194.

Thémata. Revista de Filosofía N56 (2017) pp.: 255-284. 
es acto como co-ser o co-existencia, la distinción real ser y esencia, por más que caracterice al hombre como criatura, no es la dualidad radical". ${ }^{29}$

La intimidad de sentido personal por ser co-luz que se alcanza es conocida por el hábito como sentido sin réplica de otro sentido superior, aquella réplica que no se es, y que se busca como encuentro con el sentido absoluto. Es decir, el co-sentido como búsqueda es ya orientación a la Luz que responde a la intimidad luminosa de co-luz abierta que es el acto de ser creatural, pues no es co-luz única, sino además trocado en co-sentido aceptante abierto a otro sentido superior.

En tanto que ámbito interior, el co-sentido no es solo transparencia de luz intelectual íntima metódico-temática, sino que se abre activa en dualidad radical ${ }^{30}$ luminosa y libre hacia adentro, trocándose como búsqueda inagotable de más sentido como la réplica que no puede quedarse sin resolver. Por ser la co-luz inagotable sin réplica, es activa. Así al alcanzarse, la trasparencia como tema de su método de luz noético ${ }^{31}$, se conoce en su dinamismo de co-sentido trascendental sin término. Por tanto, el co-sentido, es intelecto libre como búsqueda aceptante de un Sentido superior que le corresponde como réplica ${ }^{32}$. El co-sentido personal es apertura luminosa que busca su réplica de Luz Originaria. Lo cual indica

29. Polo, L., Antropología, I, 177. En la misma obra Polo también agrega: "El hombre no se limita a ser, sino que co-es. Co-ser designa la persona, es decir, la realidad abierta en intimidad y también hacia afuera, por tanto, co-ser alude a ser-con”. Polo, L., Antropología, I, 32. También dice: "La existencia humana, se alcanza. Yo diría que gnoseológicamente es el hábito de sabiduría: ese el modo como se alcanza la existencia humana". Curso de Antropología Trascendental, México, 1987, pro manuscripto, lección 3, 16.

30. Con relación a la dualidad intima Polo afirma: "La libertad es el transcendental personal más próximo a la co-existencia, con el que esta se dualiza de inmediato o directamente. Se trata de la primera dualidad en los trascendentales antropológicos, que se corresponde con la intimidad como apertura interior. La segunda dualidad se corresponde con la intimidad como apertura hacia adentro, según la cual se descubre que la carencia de réplica no puede ser definitiva”. Polo, L., Antropología, I, 205.

31. "Hay todavía un hábito del intelecto, que es el hábito de sabiduría, cuya temática trasciende el orden metafísico. A mi modo de ver, con este hábito se conoce la coexistencia del ser personal humano con el ser del universo y, en definitiva, con Dios". Polo, L., Curso de teoría, IV/1, 43.

32. "En suma, el descubrimiento de la intimidad como apertura interior es inseparable del valor activo, libre, de la co-existencia. Sin el descubrimiento de la libertad, la carencia de réplica anularía por completo la co-existencia. Si la persona fuese única, la intimidad no sería activa y no existiría. Por consiguiente, es un error aseverar que la persona carece de intimidad”. Polo, L., Antropología, I, 205.

Thémata. Revista de Filosofía $\mathrm{N}^{\circ} 56$ (2017) pp.: 255-284. 
que el co-sentido es puro dinamismo en actividad cognoscente orientado a ese sentido superior aceptándolo.

Como además luminoso, el co-sentido es sobrar de luz transparente que no se agota en su dualidad de co-luz solidaria con la sabiduría ${ }^{33}$ en cuanto carácter de además metódico. La luz metódica en la trasparencia luminosa interior temática es inagotable y, por tanto, activa. Así, la co-luz cognoscente activa en tanto que intellectus ut co-actus trascendental se trueca en búsqueda-aceptante de un tema superior, es decir, el ámbito de co-luz íntimo libre trocado por el intellectus ut co-actus en búsqueda-aceptante trascendental busca la Luz Originaria, aceptándola, lo cual refiere a un dinamismo luminoso de sentido que, por una parte, no se desfuturi$z a^{34}$ por ser inagotable orientado a su tema, el Sentido Originario; y, por otra, indica que ser aceptante del Sentido Originario significa apertura amorosa donal, pues la aceptación creatural es ya ofrecimiento en correspondencia desigual de su sentido a modo de don de la propia luz. Por eso el encuentro desigual de ámbitos luminosos de sentido es amoroso en dos modos de la dualidad amorosa radical, desde el Sentido Originario como Don de Luz y desde el co-sentido creatural como aceptación-donal de la propia.

Por su parte, el Sentido Originario es también apertura íntima pero como ámbito de amplitud máxima en el que incluye al sentido creatural humano como semejante, dado que el co-sentido creado como co-ser es intimidad de co-sentido en búsqueda-aceptante en semejanza de la Luz Originaria; además de co-sentido luminoso que no se detiene. El co-sentido en tanto que ámbito de sentido luminoso creatural distinto es incluido en una intimidad más neta, el dentro de máxima amplitud del Sentido Originario como Identidad. Por la inclusión en el ámbito superior, el ámbito inferior de transparencia luminosa del co-sentido creatural se amplía en

33. "La sabiduría es la más exacta de las ciencias. Así pues, el sabio no sólo debe conocer lo que sigue de los principios, sino también poseer la verdad sobre los principios. De manera que la sabiduría será intelecto y ciencia, una especie de ciencia capital de los objetos más honorables". Citado por Sellés, quien al respecto dice que si la sabiduría "juzga de las demás ciencias, lo cual indica que es superior a ellas”. ArISTóteLES, Ética a Nicómaco, 1. VI, cap. 5 (BK 1141 a 1620). Cfr. Sellés, J.F., "El hábito de sabiduría según Leonardo Polo", cit.

34. Cfr. Sellés. J.F., "La distinción entre la Antropología y la Metafísica”, Studia Poliana, 13 (2011) 112. "A mi modo de ver eso que llamo ‘desfuturización del futuro' es algo muy semejante a lo que se llama (sin llegar a describirlo del todo bien) el evo. La persona no es temporal sino que es evieterna. La evieternidad se escribe bien como una preeminencia del futuro y no tiene que pasar a ser ahora. No está obligado a pasar a ser ahora, y mucho menos a hacerse pasado. El tiempo está por debajo de la persona". Polo, L., Antropología, I, 118; "Alcanzar a co-ser acompañando, co-existir, equivale a además, y cabe describirlo como futuro sin desfuturización”. Ibidem.

Thémata. Revista de Filosofía Nº56 (2017) pp.: 255-284. 
posibilidad de sentido donal, es decir, de sentido otorgante de su luz a sus dualidades inferiores y a otros sentidos personales.

En suma, el co-sentido personal es además luminoso distinto de toda la realidad creada que como ámbito íntimo de co-luz cognoscente y activo se abre hacia adentro trocándose en búsqueda-aceptante, es decir, como intelecto amoroso orientado a su tema en tanto que réplica de Sentido superior. El ámbito íntimo de sentido Originario no es el principio de la realidad extramental: "La búsqueda no se advierte en la persistencia. El acto de ser creado como primer principio se distingue, sin más, de la realidad personal. En la Identidad Originaria la búsqueda carece de sentido". ${ }^{35}$ Por la inclusión en el ámbito del Sentido Originario, el sentido creatural ensancha su dinamismo de co-sentido íntimo capaz así de más ofrecimiento y otorgamiento de su luz.

El ámbito interior del co-sentido es abierto como co-acto luminoso, es intensidad ${ }^{36}$ transparente y luminosa por la insistencia de la luz metódica de la sabiduría en la luz íntima el intelecto personal en dualidad solidaria radical sin término. La sabiduría es luz en tanto que trasparenta el dinamismo luminoso del co-sentido trascendental, por tanto abierta o co-existente. A la par, el co-sentido es ámbito de luz íntima de intelecto personal que la atraviesa por dentro; por eso, la transparencia del co-sentido luminoso no es fija como el cristal, sino dinámica, pues es co-luz en puro sobrar luminoso cognoscente inagotable, es decir, además como trasparencia cognoscente, libre y donal que asciende orientado a su Origen de Sentido siendo elevado por la Luz Originaria. El sobrar luminoso de la sabiduría como método de luz es además inagotable según indica Polo:

El carácter de además es el método con el que se alcanza la coexistencia humana, pero en sentido más propio, además equivale a coexistencia.Por eso el hábito de la sabiduría no tiene término. Con otras palabras, el hábito de sabiduría no acaba nunca porque la persona tampoco acaba nunca. ${ }^{37}$

La congruencia de los dos miembros en la dualidad del co-sentido y el hábito de la sabiduría radica en su solidaridad luminosa metódico-temática. Pero el co-sentido como tema es superior al método, pues se distingue de él, aunque es solidario con él por incluirlo en su luz. El co-sentido como transparencia es insistencia de luz intelectual en la luz del hábito de sabiduría incluido en el interior de su núcleo trascendente de sentido

35. Cfr. Ibidem, 205.

36. "La intensidad de la transparencia es la luz intelectual por dentro, pues ese dentro es luz". Ibidem, 197.

37. Ibidem, 194.

Thémata. Revista de Filosofía N56 (2017) pp.: 255-284. 
por inclusión generosa de su sobrar de luz en la luz en tanto que co-luz de valor dual metódico-temático. El co-sentido indica co-luz personal: " $E l$ sentido metódico de la trasparencia ha de alcanzarse, pues sin él tampoco se alcanza su sentido temático". ${ }^{38}$

El hábito de sabiduría como método cognoscitivo es carácter de además indisolublemente solidario con su tema, el además de co-sentido personal o co-luz al que alcanza. Por tanto, el método es también además de luz cognoscente de su tema que, como núcleo sobrante de luz trascendental, lo tensiona en tanto que co-sentido para alcanzarse; es decir, el método es luz interior al tema luminoso al que alcanza; por tanto apertura de co-luz. Pero el alcanzar de la luz en la luz no es proceso, sino luz solidaria que se conoce como dinamismo de sentido íntimo. Es la sabiduría como hábito metódico la que ejerce lo que Polo denomina la tercera dimensión del abandono del límite mental, conocimiento para descubrir la intimidad humana como sentido personal, superior a la razón propia del inteligir la realidad objetual.

De acuerdo con la tercera dimensión del abandono del limite mental se alcanza la coexistencia humana. La coexistencia humana ni se advierte, ni se halla, ni permite demorarse en ella, sino que se alcanza. A ese alcanzar es inherente lo que llamo carácter de además. ${ }^{39}$

En definitiva, el abandono del límite mental tiene cuatro dimensiones según los temas a conocer superiores al conocimiento objetual ${ }^{40}$. La tercera dimensión es el método de la sabiduría como luz que alcanza el núcleo de sentido personal que posibilita la ampliación de la antropología como saber de sentido trascendental, es decir, como saber acerca del acto de ser personal humano que, por ser co-luz libre, trasciende el ámbito de la metafísica centrada en el estudio de los actos de ser necesarios.

El carácter de además es un sobrar de luz dinámica de sentido, es decir, de intelecto personal trascendental, que no se detiene en el límite mental, sino que se desaferra a la par que alcanza su tema, que es el

\section{Ibidem, 199.}

39. Ibidem. 117. Sobre la coexistencia como sentido íntimo Polo agrega: "La coexistencia, la ampliación del orden de los trascendentales, es la persona, la intimidad irreductible en la medida en que se alcanza: ese alcanzar es indisociable de su ser". Ibidem. 117.

40. "El conocimiento objetivo es aspectual o intencional, y versa sobre las formas físicas sin explicitar que realmente son concausales. Pero no versa sobre las dimensiones superiores de la esencia del hombre... Tampoco cabe conocimiento objetivo de la voluntad o de la inteligencia, pues el conocimiento objetivo parte de la iluminación de los sensible, y las potencias no son sensibles". Ibidem, 112.

Thémata. Revista de Filosofía $\mathrm{N}^{\circ} 56$ (2017) pp.: 255-284. 
núcleo del co-sentido personal como conocer trascendental el co-sentido luminoso. ${ }^{41} \mathrm{El}$ co-sentido es intelecto radical, por ello superior, que ilumina todo el conocer humano a la vez que se orienta al conocimiento de un tema superior, la Verdad que le corresponde como Sentido Originario ${ }^{42}$.

Por su parte, se ha indicado que el hábito de sabiduría es co-luz con el sentido trascendental (la persona como ser cognoscente), en dualidad luminosa solidaria con la luz que alcanza. Esta co-luz es intelecto trascendental que no se confunde con la potencia intelectual (la razón) en tanto que no la tiene como punto de partida; por tanto, no la satura, de ahí su carácter irrestricto. La luz metódica del carácter de además no se detiene en el alcance de su tema, pues es atraído en ascenso por el núcleo de co-sentido (el acto de ser personal o conocer a nivel de ser) alejándose sin parar del límite mental en cuanto punto de partida. De detenerse en el límite mental del pensamiento objetual, la luz de sentido ascendente como además sucumbiría a la fijación y no alcanzaría el co-sentido radical.

El carácter de además es el co-sentido como tema que ilumina internamente al método para abandonar su punto de partida, el conocimiento objetivo, por eso el tema es conocimiento personal radicalmente distinto del límite mental, pues es solidario con el carácter de además

41. "El conocimiento trascendental, rigurosamente hablando, debe ser transobjetivo. Transobjetivo porque se alcanza al abandonar el límite mental con actos superiores a las operaciones. Al abandonar la operación, ya no se conocen objetos, sino más que objetos. Y ese conocimiento transobjetivo es cuádruple”. Polo, L., Presente y futuro del hombre, Rialp, Madrid, 1993, 179. "Con cuádruple Polo se refiere a las cuatro dimensiones del abandono de límite mental. De las cuales la tercera es el carácter de además y la cuarta la explicación de la esencia humana. Es decir como método o modos de conocer perfecciones. En el caso de la persona la perfección es co-acto trascendental porque de carecer de esas perfecciones trascendentales que conforman el ser humano no sería persona. El método para alcanzarlas es el carácter de además". Sellés, J.F., "La distinción entre antropología y ética", Studia Poliana, 13 (2011) 124. Para Polo trascendental también significa "lo que trasciende la propia perfección personal, en concreto, apertura a la realidad personal superior, y esto porque los rasgos capitales que conforman la intimidad humana, nativamente desbordantes, tiene como norte el ser personal divino". Polo, L., Antropología, I, 125. Por tanto, la tercera dimensión alcanza el carácter trascendental del ser humano como co-ser o co-luz es decir el co-sentido personal.

42. "La actividad inquisitiva del intelecto personal es inagotable, inacabable, con un futuro interminable, libre. En ello se manifiesta la solidaridad entre el método y el tema de la sabiduría humana. Ya que esa actividad de búsqueda es inagotable e interminable porque el mismo intelecto personal, que es su tema, es así: un ser inacabable e inagotable, libre y permanentemente abierto al futuro". GARCíA, J.A., "El entendimiento humano, según Leonardo Polo”, en González, A.L., Zorroza, I., (eds.): In umbra intelligentae, Eunsa, Pamplona, (2011), 493.

Thémata. Revista de Filosofía N56 (2017) pp.: 255-284. 
como método para alejarse de él. Este método cognoscente es el hábito de la sabiduría, que sin el co-sentido solidario sería precario para alejarse sin detención del limite mental. La sabiduría es alcanzar sin respuesta o término, debido a la luz intrínseca del co-sentido personal interna en su luz, por tanto co-luz. Este alcanzar alcanza el ámbito trascendental del sentido personal como núcleo de co-luz radical.

En cuanto núcleo de co-luz de tema y método, el co-sentido no precede al hábito de la sabiduría, ni lo genera, sino que es dualidad solidaria con él. El co-sentido luminoso es miembro superior de la dualidad radical de luz, pues tira de la luz metódica o habitual para ascenderla en alcance de su transparencia insistiendo en ella como luz además de luz, sin lo cual el hábito sucumbiría por precariedad en el límite mental. Con otras palabras, como co-luz metódica la sabiduría no deriva de la luz transparente temática, sino que como co-luz es interior al núcleo luminoso que no la precede o genera. Es decir sin la luz metódica de la sabiduría no se alcanza el núcleo luminoso radical en cuanto co-sentido, porque este conocer se aleja del límite mental. A la vez que la luz del método es interna al núcleo de sentido, la luz temática es interna a la luz del método; por eso, la peculiar co-luz solidaria que es el acto de ser humano como sentido radical de carácter trascendental.

En consecuencia, alcanzarse desde la luz solidaria significa ser además de sentido que no termina de alcanzarse. De lo contrario, si el co-sentido generara el método se supondría como su tema, y se alcanzaría sin más, agotándose, cumpliéndose como método de luz iluminante al alcanzarlo, es decir, anulando la solidaridad trascendente de ser luz en la luz y, por tanto, clausurando la posibilidad de ser ámbito abierto de co-sentido luminoso. En cambio, por la solidaridad de la co-luz se abre el ámbito interior luminoso como ser, inagotable como co-existencia. En tanto que ser inagotable de luz no se termina de alcanzar. Por eso la persona insiste en ser, es decir, como núcleo personal de sentido es siempre abierto a más sentido, por eso es además de luz que a su vez se orienta a un tema de sentido superior. Es decir, la persona es ámbito interior de sentido que va a más sentido. Como coexistencia el núcleo personal es sentido abierto porque no se trata de una luz única, sino co-luz abierta a más luz. Como co-luz el núcleo es sentido abierto a su tema en conversión dual con el intelecto personal, a la par que co-luz atravesante de lo inferior desde el ámbito radical, o sea, el co-sentido es también luz generosa para advertir

Thémata. Revista de Filosofía $\mathrm{N}^{\circ} 56$ (2017) pp.: 255-284. 
el acto de ser del universo y para iluminar el ámbito esencial o manifestativo del hombre.

En efecto, el núcleo de la co-luz personal es co-sentido como apertura co-existente ${ }^{43}$, es decir, como ámbito abierto de intelecto activo que se distingue a la vez que es semejante al Sentido Originario. El co-sentido no es ámbito pasivo iluminado por el Sentido superior, sino co-luz insistente como intimidad que se orienta a un sentido superior distinto por ser Originario, esto es, el co-sentido como acto de ser personal creado se distingue en dependencia del Sentido personal como Origen. Como el co-sentido se abre al Origen del Sentido, es decir a la Luz como tema, el sentido personal creatural busca otro Sentido que es Persona. En la Luz Originaria de Sentido el co-sentido se reconoce y es reconocido como verdad personal. Por orientarse como intelecto trascendental en la búsqueda de la Verdad como Origen Luminoso de Sentido el co-sentido personal es sentido creatural también abierto a otros sentidos personales creaturales.

$\mathrm{El}$ otorgar de luz esencial que se dona hacia afuera a la coexistencia manifestativa, es derivada del dinamismo luminoso activo cognoscente radical que como búsqueda aceptante es ya encuentro de esplendor con su tema, el Sentido Originario que lo performa con su atravesar amoroso cognoscente incluyéndolo dentro de sí donándole su Sentido, es decir, como fuerza luminosa de dones que ascienden el dinamismo de sentido creatural en confianza de búsqueda personal $(f e)$ en el destino también personal, en aceptación-donal del Origen como su tema hacia el que orienta su conocer activo (esperanza), y al que orienta todo lo inferior a la vez que se le ofrece como co-sentido personal y le ofrece sus obras dotadas de sentido (amor). Escribe Sellés:

Ese es nuestro destino, que más que como "autotrascendimiento", es pertinente verlo como atracción divina, puesto que es la progresiva activación de nuestra libertad, conocer y amar personales. La filiación divina está acompañada de las llamadas virtudes sobrenaturales: la fe, la esperanza y la caridad. Cada una de esas virtudes eleva un radical personal distinto: la esperanza eleva a la libertad personal; la fe al conocer personal y el la caridad al amar personal. La superabundancia de la aceptación humana al don amoroso divino impele al conocer personal a ser confiado y a la libertad personal a ser esperanzada. Esas tres virtudes tienen como método la elevación de los propios radicales personales humanos, y como tema a Dios, pero

43. "El término co-existencia no hace referencia de modo radical a la apertura hacia fuera de la existencia humana -es decir, a la existencia con distintos seres-, pues tal apertura por sí sola carece de explicación: sólo si de modo radical el ser humano está abierto hacia sí -si la apertura es interna a la persona humana- es posible justificar una apertura radical del ser humano hacia seres distintos. En síntesis: la apertura hacia fuera depende de la apertura íntima”. Pí́ Tarazona, S., Idea cristiana del hombre, Actas del III Simposio internacional sobre fe cristiana y cultura contemporánea, Eunsa, Pamplona, 2002, 211.

Thémata. Revista de Filosofía $\mathrm{N}^{\circ} 56$ (2017) pp.: 255-284. 
cada una de ellas de un modo distinto. La esperanza mira a Dios como liberador, salvador, del propio límite ontológico; la fe, como conocimiento transparente seguro y completo del sentido personal que Dios nos otorga; la caridad, como aceptación divina de nuestra donación personal. Esas virtudes son el incremento de los radicales personales humanos. ${ }^{44}$

Así, el sentido personal no surge de lo inferior, sino que otorga su luz a lo inferior para iluminar por el encuentro esencial otras esencias personales; por tanto, es también aceptación del don esencial de sentido del otro, en tanto que apertura donal que es también aceptación en el nivel manifestativo. Por eso, el dinamismo íntimo o su opacidad se desvela en parte por las obras, los gestos, las palabras, las actitudes, en consistencia de sentido radical o no, es decir, como manifestación del dinamismo de luz unitiva intelectual del sentido o como disgregación biográfica con el sentido radical que se es y cuyo dinamismo asciende en tanto que se orienta como respuesta a la llamada de ser búsqueda-aceptante de un Sentido superior ${ }^{45}$.

\section{Co-sentido como búsqueda aceptante de su tema}

La criatura humana es co-sentido personal, luz en la luz ${ }^{46}$ que busca su tema ${ }^{47}$. En tanto que dualidad luminosa el co-sentido significa amplitud íntima como apertura sobrante de luz intelectual. El co-sentido como luz intelectual humana no es luz iluminante a modo de difusión como foco de la luz divina ${ }^{48}$ en el intelecto personal, sino que el co-sentido

44. Sellés, J.F., "El destino de la persona humana. Un enfoque poliano”, en GARCíA, J.A., - PADIAL, J.J., (coords.), Autotrascendimiento, Universidad de Málaga, Málaga, 2010, 205-226,17.

45. "Ante todo, y como se trata de una actividad libre, hay que observar que se trata de una pluralidad de ejercicios activos, entre los cuales el intelecto personal libremente transita. A este tránsito Polo lo denomina la metalógica de la libertad, con la cual formula la entera personalización del entendimiento humano; e incluye dos eventuales retiradas: desde el dar y aceptar interpersonal a la generosidad de la persona, y desde ésta hasta el disponer esencial". García J.A., "El entendimiento humano, según Leonardo Polo", en González, A.L., Zorroza, I., (eds.): In umbra intelligentiae, Eunsa, Pamplona 2011, 490.

46. "El intellectus ut coactus es la luz penetrada de luz, pues, como tema del hábito de sabiduría, se alcanza según el carácter de además. Este hábito es solidario con su tema porque, de otro modo, la persona seguiría quedando inédita”. Polo, L., Antropología, I, 180.

47. "No es admisible que el intlellectus ut co-actus carezca de tema, por más que sea el acto intelectual superior del hombre, ya que sin correspondencia temática la noción de acto cognoscitivo es un contrasentido". Polo, L., Antropología, I, 180.

48. Polo aclara: "Según mi propuesta, al sentar la solidaridad del hábito de sabiduría con

Thémata. Revista de Filosofía $\mathrm{N}^{\circ} 56$ (2017) pp.: 255-284. 
es además de co-luz solidaria efusiva ${ }^{49}$, es decir, dualidad de la luz metódica noética de la sabiduría con el intellectus ut actus o conocer personal, como intensidad transparente ${ }^{50}$ de luz, que por ser ámbito de co-luz activo se trueca en dinamismo luminoso superior libre ${ }^{51}$ búsqueda-aceptante ${ }^{52}$ de su Origen. Polo aclara respecto del Origen como tema de Sentido superior:

\begin{abstract}
Desde luego la filosofía puede llegar a Dios, y la mejor manera de hacerlo es sostener que el acto de ser de Dios es superior al acto de ser distinto realmente de su esencia[...] siguiendo la antropología se llega al acto de ser originariamente idéntico con mayor intensidad. En metafísica, el primer principio de identidad se advierte
\end{abstract}

el intelecto personal, se alcanza la interioridad de la luz -la luz es además luz-, la cual es superior a la noción de foco. Y como esa solidaridad es creada, debe admitirse que la noción de foco no es atribuible al intelecto divino: si el intelecto personal creado no es focal, menos aún lo será el divino. Con la noción de foco se olvida que la Identidad es Originaria; de ningún modo la noción de foco es originaria, pues es el punto del que arranca una difusión”. PoLo, L., Antropología, I, 198

49. "Ahora bien, si la persona como tal no entra en relación con lo que no es ella en forma de asimilación (aqui Polo se refiere al tipo de permanencia del ser extramental que requiere el recurso de elementos extraños para ser asimilados mediante actividad), resulta que es capaz de un modo de relación que podría llamarse efusión de sí misma. La efusión es una expansión no determinada por una asimilación previa, y, por lo tanto, aportada. Este otorgamiento nos pone ante la mirada de la libertad. Que la persona es libre significa, ante todo, que su manifestación es efusiva". Polo, L., Sobre la existencia cristiana. Eunsa, Pamplona, 1996, 260.

50. "El hábito de sabiduría se describe como actuosidad insistente en la transparencia del intelecto personal en tanto que esa insistencia no tiene nada que ver con una culminación". Polo, L., Antropología, I, 128.

51. "Si el conocimiento de que Dios existe se incoa nativamente según el hábito de los primeros principios y según el de sabiduría, ¿por qué los hombres requieren de tanta argumentación, esto es, de demostración respecto de este tema? No puede ser por otro motivo que porque la luz natural que permite tal conocimiento es susceptible de oscurecimiento en el transcurso de esta vida. En esos casos (al margen de la personal culpabilidad) se hace necesaria la demostración de la existencia de Dios. Pero para quien no haya cedido al oscurecimiento y conoce libremente que Dios existe, no requiere de demostraciones necesarias, pues la libertad es superior a la necesidad". SELlés, J.F., "El hábito de la sabiduría según Leonardo Polo", cit., 88.

52. "Hay que decir en atención al carácter de además, que el tema correspondiente al intelecto personal es inagotable e inabarcable, y que su búsqueda es orientada porque la carencia de réplica no puede ser definitiva. Dicha inagotabilidad comporta que la búsqueda de tema equivale a la búsqueda de réplica. Ahora bien, como la réplica buscada ano lo es sólo del intellectus ut co-actus, es obvio que la búsqueda no es el conocimiento más alto de ella”. Polo, L., Antropología, I, 225. También aclara: "Buscar una réplica más alta que el propio intelecto personal confirma que la persona humana es el adverbio en busca del Verbo". Ibidem, 226.

Thémata. Revista de Filosofía N56 (2017) pp.: 255-284. 
como Origen. En antropología se descubre que ese Origen es persona. ${ }^{53}$

En tanto que ámbito interior de tema y método noético el intelecto personal no es luz única, sino dual con la sabiduría o carácter de además, es decir, como sentido personal que se descubre sin réplica. En tanto que es luz abierta a un sentido superior ${ }^{54}$, no como dualidad sino como tema, se trueca en búsqueda en conversión radical. Así el co-sentido se activa hacia adentro como búsqueda-aceptante, es decir, el co-sentido como búsqueda de su réplica de sentido superior es conversión trascendental del conocer personal, en tanto que apertura de luz intelectual abierta, con la actividad pura libre; por tanto, luz de sentido dinámica efusiva que en tanto que es búsqueda intelectual es aceptante de la Verdad como tema. La aceptación es amorosa en tanto que el tema también lo es.

El dinamismo de co-sentido respalda con su intensidad solidaria el hábito de la sabiduría ${ }^{55}$ en tanto que co-luz en él. Por eso, es sentido personal abierto al conocimiento de otros sentidos personales en intimidad, es decir, sin manifestarse. Si por la esencia se realiza la coexistencia donal de sentidos manifestativos, por la la sabiduría solidaria como co-luz del co-sentido radical, la intimidad, es luz abierta al conocimiento de otras intimidades de sentido. Si bien por la estructura amorosa propuesta por Polo se entiende que el sentido es donal a otros sentidos en el ámbito esencial, es decir, a través de su manifestación, el conocimiento personal más profundo de los otros sentidos personales creaturales no se realiza en el nivel del inteligir, pues se estarían suponiendo como temas inteligibles. Si el conocer personal en tanto que dinamismo de sentido es búsqueda aceptante de su tema, aún cabe iluminación solidaria en su dualidad interior como ámbito íntimo también cognoscente por ser co-luz, o sea, co-sentido como co-existencia. Este conocer de la transparencia solidaria con la sabiduría conoce a nivel personal lo que posibilita el conocimiento de otros

\section{Polo, L., Antropología, I, 144.}

54. "Si se ahonda en esta temática se puede sostener lo siguiente: sólo si Dios existe puede existir el ser humano, pues Dios es el único que puede garantizar que la co-existencia del ser humano no sea desdichada, ya que sólo Dios puede reconocer y aceptar de modo íntegro a cada persona humana". PIÁ TARAZONA; S., "El carácter filial de la co-existencia humana", en Idea cristiana del hombre. Actas del III Simposio internacional sobre fe cristiana y cultura contemporánea, Eunsa, Pamplona 2002, 211.

55. "De modo que cuando uno alcanza su ser personal con el hábito de sabiduría conoce las demás realidades, de tal manera que el hábito de sabiduría nos sitúa como personas ante el marco de la entera realidad, acerca de la cual uno se las tiene que haber personalmente, libre y por tanto responsablemente". SeLLés, J.F., "El hábito de la sabiduría según Leonardo Polo", cit., 90.

Thémata. Revista de Filosofía N56 (2017) pp.: 255-284. 
sentidos personales ${ }^{56}$, aunque ese conocer permanezca íntimo, pues solo se manifiesta hacia afuera a través de la esencia, es decir en el descenso de la luz del co-sentido derivada como otorgamiento a las relaciones interpersonales. Pero el núcleo de sentido radical no respalda en solidaridad luminosa los otros hábitos innatos en su descenso de luz a la esencia, por lo que la luz de sentido radical disminuye en intensidad a medida que desciende a los otros hábitos innatos; por ello, los hábitos de los primeros principios y la sindéresis no son co-luz, como la sabiduría, sino luces iluminantes derivadas, es decir, sin la intensidad del co-sentido luminoso trascendental. También por eso el co-sentido aún manifestado en su cuerpo es novedad en tanto que inicio como ámbito de sentido biográfico ${ }^{57}$.

En cambio, en el ascenso del dinamismo del co-acto de sentido como búsqueda-aceptante de su tema, se descubre como co-sentido creadoen semejanza, escribe Polo: "Aunque el hombre sea creatura, su brotar en el orden del ser se mantiene en intimidad. Por eso, aunque el hombre no sea la intimidad perfecta Tripersonal, que es Dios, también es persona". ${ }^{58}$ Así, el co-sentido se descubre en semejanza de la Luz Originaria ${ }^{59}$, es decir, no como cristal que refleja la luz de un foco, sino como dualidad lu-

56. "Sin la preexistencia del universo físico y de otras personas humanas es inviable la aparición de un nuevo ser humano. Si se atiende a esta sencilla cuestión se descubre que, desde el inicio, la persona humana está abierta en su co-existir a distintos tipos de existencia -o de coexistencia-; su acto de existir -o acto de ser- no es un acto de existir solitario, sino más bien solidario, abierto a lo demás. En efecto, la persona humana existe desde el principio con el universo físico y con las demás personas; por eso, a su característico modo de existir con distintas criaturas se le ha denominado co-existencia". Pí́ TARAzona, S., "El carácter filial de la co-existencia humana”, cit., 211.

57. "De todos modos, el coexistir tiene que ver con la nada en la medida en que es situado en la historia como un Novum: sólo el ser generado el cuerpo de cada hombre cabe decir que comienza la co-existencia humana, o que es situada en la historia." Al respecto de ser novum Polo aclara: AI. P. 187 “...desaferrase de la constancia de la presencia mental hace superfluo que el carácter de además sea un comience: más aún, se distingue del comenzar por ser novum. Como novedad, el carácter de además permite que la vuelta sea un demorarse cuyo ápice es el yo". Polo, L., Antropología, I, 141.

58. Polo, L., Sobre la existencia cristiana, Eunsa, Pamplona, 1996, 260.

59. "La co-exisencia es creada, pero eso no quiere decir que sea causa causada (así se distingue de la persistencia). De esta manera se rescata la noción tradicional del hombre como imago Dei: e hombre es creado como imago: en cambio la persistencia es vestigium Dei. El hombre es imago porque es persona y, por tanto, capaz de abrirse a su ser conocido por Dios. En la persistencia dicha apertura no existe". Polo, L., Antropología, I, 178.

Thémata. Revista de Filosofía №56 (2017) pp.: 255-284. 
minosa radical dinámica que es ámbito íntimo de luz activo, cognoscente y aceptante-donal distinto ${ }^{60}$ del Sentido Originario ${ }^{61}$.

En tanto que el co-sentido es co-luz íntima, activa que se trueca en búsqueda-aceptante-donal ${ }^{62}$, como búsqueda comporta que el tema del co-sentido es el Sentido Originario. Ser búsqueda implica la destinación al encuentro esplendoroso ${ }^{63}$ con la Luz como Origen. En el encuentro con su tema, el co-sentido personal es elevado a modo de dinamismo ascendente por la conversión de los radicales personales que como coexistencia libre y amorosa aceptante-donal, siguen la búsqueda del intelecto personal orientado a su tema al cual se destina, por ser éste Origen de su luz personal. Como el Sentido Originario es Trascendens ${ }^{64}$, atraviesa el co-sentido creatural con su Luz, es decir, lo conoce como intimidad. La

60. Con relación a la distinción del carácter de además y su esencia Polo escribe: "El carácter de además es distinto realmente de la esencia del hombre y, por tanto, de los hábitos adquiridos... más distinto de Dios que de la nada, y más distinto de la nada que de la esencia". PoLo, L., Antropología, I, 120.

61. "Actualmente está en crisis la metafísica y parece en auge la antropología. Con todo, permítase una pregunta para examinar la altura de las antropologías vigentes: ¿indagan éstas acerca del destino humano? Las menos aluden al "fin" de la vida humana; las más, ni siquiera a ello. En las que atienden al fin, lo entienden como término de esta vida, pero se advierte que no se atreven a explicar desde el fin la presente vida humana. Con todo, téngase en cuenta que "fin" no equivale a "destino". El primero consiste en el bien -la felicidad o bienaventuranza, en términos clásicos -. El segundo, en la realidad personal divina". SELLÉs, J.F., "El destino de la persona humana. Un enfoque poliano", en García, J.A., Padial, J.J. (coords.), Autotrascendimiento, Universidad de Málaga, Málaga, 2010, 1.

62. "Amar a Dios es transcendental en tanto que la persona prefiere a Dios. Esa preferencia es dilectio. Por más que la persona no sea capaz de hacer de su amar un don trascendental-pues puede dar su amor a modo de don, pero no convertir su don en persona-, aun así, el amor, está en la persona en estado de espera, es decir, como amar en busca de aceptación. El amar espera ofrecer el don, y que ese don sea aceptado". Polo, L., Antropología, I, 227.

63. "Dios es el tema del acto cognoscitivo superior humano en tanto que en este tema está incluido también, temáticamente, dicho acto cognoscitivo. En este sentido, puede hablarse de la comunicación donal de un tema doble: Dios e intelecto humano". Polo, L., Antropología, I, 226.

64. Dice Polo: "Trascender- que significa ir más allá, trans-cando-, comporta la completa superioridad de Dios, pero no su alteridad-Dios como lo absolutamente otro-; puesto que se llega a Él desde la dualidad llamada co-existencia (Si Dios fuese lo absolutamente otro la dualidad humana no sería creada) [...] Dios trasciende el entero sobrar [...]"El acceso antropológico a Dios se distingue del metafísico. En metafísica, Dios es la Identidad Originaria, un primer principio que no se macla con el principio de la no contradicción [...] En cambio, entender a Dios como trascendens respecto de la co-existencia comporta que la co-existencia depende de Él en cuanto que ella es trascendentalmente dual [...] Dios como trascendens es, asimismo, Originario. Ahora bien, como trascendens a la coexistencia, Dios ha de ser originariamente Persona. Si lo que caracteriza a la persona humana es la ausencia de réplica, en la Persona Originaria esa carencia no puede tener lugar”. Polo, L., Antropología, I, 178.

Thémata. Revista de Filosofía №56 (2017) pp.: 255-284. 
elevación requiere ser aceptada por el co-sentido creatural. Por tanto, el co-sentido es radicalmente apertura aceptante-donal de su tema. Apertura, para ser atravesado por la Luz del Sentido Originario. Aceptante, porque el co-sentido ama en aceptación de la Luz originaria, pues es dualidad de aceptación y búsqueda, es decir, de amar y conocimiento personal. Polo describe así respecto del aceptar Divino al co-sentido creatural en el encuentro de esplendor de sentidos:

Lo anterior comporta una jerarquía de actos donantes y aceptantes. Dios acepta misericordiosamente, no necesariamente. No considerar temáticamente la elevación sobrenatural no quiere decir limitarse al orden natural. Lo que está en juego en antropología trascendental es el ser personal. ${ }^{65}$

El co-sentido es también apertura donal ${ }^{66}$, porque como sobrar de co-luz, su búsqueda es ya dar como ofrecimiento de sí en orientación a su tema. La orientación del co-sentido a su tema implica destinarse en ofrecimiento unitivo de su realidad de sentido como acto de ser y esencia. Polo agrega sobre el ofrecimiento: "Desde luego, lo que el hombre otorga a Dios es insignificante. Pero la aceptación divina dota a la ofrenda humana de un valor superior al que de suyo tiene. Por eso, aceptar es el refrendo del don humano, sin el que no significaría apenas nada". ${ }^{67}$ Por tanto, el co-sentido en su dinamismo luminoso que asciende al encuentro con su Origen, incluye los hábitos adquiridos ${ }^{68}$ esenciales dotándolos de sentido

65. Polo, L., Antropología, I, 222.

66. "Cuando se destina la entera actividad humana como don adecuado a la divinidad, nuestra existencia adquiere un sentido donal, nuestra vida biológica, nuestro producir y nuestro donar imperfectos son mediados donalmente por el destino mismo, y alcanzamos una perfección que está por encima de nuestras posibilidades naturales, obteniendo para nosotros y para los demás la plenitud de la vida y de la libertad. Tal plenitud de vida y de libertad, ala que estamos donalmente llamados por el destino, sólo puede, pues ser alcanzada por la aceptación de la mediación donal perfecta del destino mismo". FALGUERAS, I., Crisis y Renovación de la metafísica, Servicio de Publicaciones e Intercambio científico de la Universidad de Málaga, Málaga, 1997, 69.

67. Polo, L., Antropología, I, 222.

68. "Los hábitos adquiridos son susceptibles de crecimiento, pero si los innatos están orientados (primeros principios) por sus temas o transparentan sus temas (sabiduría), cabe señalar que esta orientación o transparencia tampoco admite consumación. Así, con el hábito de sabiduría se podrá conocer cada vez más y mejor lo divino, conocimiento que coimplicará, a su vez, un mayor conocimiento propio". SELLÉs, J.F., "El hábito de sabiduría según Leonardo Polo", cit., 92.

Thémata. Revista de Filosofía N56 (2017) pp.: 255-284. 
personal en el ofrecimiento íntimo de sentido a su tema. De ahí la relevancia de la esencia humana estrechada al dinamismo radical de co-sentido.

La congruencia solidaria del co-sentido como transparencia con la sabiduría en interioridad luminosa creada es además co-luz en tanto que imagen del Sentido Originario como Luz creadora. Se trata, en cierto modo, de una congruencia superior a la dualidad del co-sentido como búsqueda con su tema, pues visto desde el Sentido Originario como Trascendens, la búsqueda creatural es ya un atravesar superior de su Luz, a su vez que la inclusión del co-sentido distinto creatural en su ámbito de máxima amplitud libre, luminoso y amoroso, es decir, en tanto que el co-sentido como búsqueda aceptante de su tema se destina al encuentro esplendoroso es ya incluido en la intimidad originaria que lo atraviesa con su Luz elevando su dinamismo. Por ser idéntico, el Sentido Originario no requiere de la luz del co-sentido creatural, sino que lo incluye en su interioridad en un donar de Luz como Don que, de ser aceptada por el co-sentido, lo trasciende en dualidad desigual de luces. Así, el co-sentido orientado a su destino en búsqueda-aceptante del Sentido Luminoso es elevado por el esplendor de Luz, que lo restaura en su dinamismo luminoso ascendente a su tema.

Con otras palabras: como la sabiduría es carácter de además como método noético de luz que alcanza el sentido personal, es intrínseca en tanto que solidaria al núcleo de sentido en distinción de los otros hábitos innatos. El alcanzar sin término el núcleo de sentido personal comporta para el carácter de además metódico conocer el interior de su dinamismo de luz inagotable. Si tuviera término, no sería solidario con el núcleo inagotable de co-sentido personal. Por otra parte, sin la solidaridad de la sabiduría el co-sentido no se alcanzaría como transparencia, es decir, el alcanzar es luz que conoce el dinamismo del intelecto personal como co-luz. Pero la sabiduría no alcanza el tema del co-sentido, puesto que el núcleo de co-luz es conocimiento superior que se trueca en búsqueda-aceptante de otro sentido personal superior a él en tanto que Trascendens; es decir, así como el co-sentido es tema de la sabiduría, que frente al encuentro con su propio tema, es método trascendental cognoscente capaz de conocerlo sin agotarlo, el co-sentido personal como búsqueda se orienta a su tema abriéndose en aceptación donal a la Luz originaria.

No hay en la búsqueda solidaridad con el hábito, sino que el co-sentido trasciende el ámbito de co-luz íntimo en actividad de búsqueda aceptante hacia adentro. Por tanto, el co-sentido como intelecto personal se abre a una nueva dualidad sobre el ámbito interior luminoso en tanto que búsqueda-aceptante ${ }^{69}$ de una luz superior. La búsqueda cognoscente

69. Dice Polo: "el hombre coexiste con el Absoluto en la forma de una búsqueda de aceptación

Thémata. Revista de Filosofía N56 (2017) pp.: 255-284. 
del intelecto personal como co-sentido radical en conversión trascendental activa y aceptante amorosa-donal, indica orientación de este dinamismo de sentido personal a su tema como Sentido Idéntico no dual, es decir como Verdad que responde a la búsqueda-aceptante de la verdad personal de la criatura. Así el Sentido Originario es destino del además de sentido o ámbito de acogida sin término para el co-sentido creatural. El tema del co-sentido es réplica a la búsqueda de sentido superior, pues lo trasciende en un encuentro esplendoroso mutuo de sentidos personales en tanto que Sentido Originario, intelecto abierto activo, amoroso e incluyente. Al respecto de la verdad personal Murillo aclara:

La ampliación de lo trascendental permite conceder a esta afirmación un valor ontológico. Para Polo la verdad no es terminal, algo en lo que se descansa, y la actitud que con ella se corresponde no es una especie de estupor o parálisis. El sentido personal de la verdad es la inspiración. La libertad no prescinde de la verdad, pues no puede dar sin ella, pero, al acogerla, la continua y la expresa. ${ }^{70}$

Si la Identidad Originaria se advierte como primer principio desde la metafísica, desde la antropología se alcanza como Origen de Sentido Personal ${ }^{71}$. En cuanto ámbito de co-luz íntimo personal que no acaba, el

personal". Polo, L., "La coexistencia del hombre", en Inmanencia y trascendencia. Actas de las XXV Reuniones Filosóficas, Facultad de Filosofía de la Universidad de Navarra, 1991, vol. I, 46

70. Murillo, J.I., "Diálogo y verdad en la antropología trascendental de Leonardo Polo", en: VV. AA., Verdad y diálogo, cit., 384.

71. "La segunda y cuarta dimensiones demuestran la existencia de Dios, aunque de modo distinto cada una de ellas. La primera y la tercera, por su parte, no la demuestran, sino que la muestran, aunque también diversamente cada una de ellas. Ahora bien, lo que interesa resaltar aquí es que todos estos modos de acceder a Dios desde el método propuesto son libres. La primera es el ejercicio libre del hábito de los primeros principios. La segunda es el salto libre de la razón al hábito de los primeros principios. La tercera es libre, porque ejercer el hábito de sabiduría lo es. La cuarta también lo es, porque iluminar la esencia humana desde la sindéresis también es libre; iluminación que rinde libre a la propia esencia humana (a la inteligencia y a la voluntad). De modo que todos esos accesos a Dios sólo "demuestran" o "muestran" para el que los acepta libremente. Para quien se empeña en rechazarlos no demostrarán nunca nada, pero, por ello mismo, pactará implícita o explícitamente con el absurdo, la falta de explicación de todo lo real (el universo, los demás y él mismo)". Sellés, J.F., "El hábito de la sabiduría según Leonardo Polo", cit., 86.

Thémata. Revista de Filosofía N56 (2017) pp.: 255-284. 
co-sentido se orienta como criatura a su tema ${ }^{72}$, la cual está incluida en el ámbito luminoso de carácter personal, es decir, el Sentido Originario.

El co-sentido personal es intelecto trascendental ${ }^{73}$ creado que se dirige a la intensidad infinita de Sentido inabarcable por ser Originario ${ }^{74}$, pero cognoscible por ser personal, es decir, como ámbito de máxima amplitud en el que el sentido personal es incluido de modo atópico, pues no le añade su luz a la Luz Originaria, sino que la máxima amplitud acoge el co-sentido creatural en su interior para trascenderlo de su Luz no obnubilándolo ${ }^{75}$ ni siendo un todo con él, sino distinguiéndolo como criatura en aceptación amorosa de su luz de co-sentido creatural.

El punto de partida del carácter de además es la presencia mental, que significa eximirse de la distinción con la nada en tanto que el punto de partida no es la nada. Por eso, la presencia mental es límite que exime de la nada a la luz del co-sentido que se aleja de él desaferrándose. Puesto que el co-sentido personal no es extra nihilum, aunque su naturaleza en parte lo es, el punto de partida marca el límite entre la manifestación de sentido personal, la esencia humana, con la esencia de la criatura extra nihilum, es decir, la esencia física extramental. Esto indica que el límite mental salvaguarda la esencia humana ${ }^{76}$ de confundirse con la esencia extramental, pues la distingue de la mera explicitación concausal de la segunda dimensión. Por eso, la primera dimensión del abandono del lí-

72. "Ser persona creada se distingue del Ser Originario, que es exclusivamente Dios, y del ser como persistencia, que no es persona. Para ser persona humana es menester ser además. Ser además cumple todas las condiciones de ser creado, pero no como persistencia, sino añadiéndose. Persistir significa no dejar que aparezca la nada; ser además es abrirse íntimamente a ser sobrando, alcanzándose: más que persistir, significa acompañar, intimidad, co-ser, coexistir". Polo, L., Antropología, I, 141.

73. Respecto del conocer personal señala Polo: "es evidente que el conocimiento del hombre no puede partir de la abstracción. La razón es muy elemental, a saber, porque se abstrae de la sensibilidad y, por tanto, en definitiva es lo sensible lo que se ha hecho inteligible y abstracto". Polo, L., El conocimiento racional de la realidad, citado por Sellés en "El hábito de la sabiduría según Leonardo Polo", cit., 91, nota 63.

74. "Para Polo desde la metafísica no se llega a Dios como persona [...] Si en metafísica, Dios se advierte como Identidad Originaria, en antropología esa advertencia ha de ser conservada y recabada, pues Dios como trascendens es, asimismo, Originario. Ahora bien, como trascendens a la co-existencia, Dios ha de ser Originariamente Persona". Sellés, J.F., "El hábito de la sabiduría según Leonardo Polo", cit., 86.

75. "La unión del hombre con Dios se realiza en el Hijo de Dios. El Hijo de Dios no es solamente un término intencional ni la meta de un despliegue operativo humano concretado antes de El. Muy al contrario, el Hijo es vida y camino para el despliegue de sí mismo. Al producirse el desarrollo de la criatura renacida, el Hijo encierra en Sí mismo, con absoluta prioridad, dicho desarrollo". Polo, L., Sobre la existencia cristiana, Eunsa., Pamplona, 1996, 279.

76. "La presencia en tal salvaguarda la esencia del hombre, es decir, la preserva de la confusión con la esencia extramental". Polo, L., Antropología, I, 188.

Thémata. Revista de Filosofía $\mathrm{N}^{\circ} 56$ (2017) pp.: 255-284. 
mite mental margina el límite mental para advertir la persistencia como comienzo extra nihilum del acto de ser del universo como principio. La advertencia es la primera dimensión del abandono del límite que no incluye la presencia mental en tanto que no suficiente para orientarse a los primeros principios como comienzo a partir de la nada, sino que requiere de la luz superior del co-sentido en descenso para abrirse al acto de ser extramental.

En cambio, el sentido personal no tiene su comienzo en la nada, sino en el Sentido Originario que es persona. En tanto que creado, el co-sentido tiene punto de partida que no es ningún comienzo, como el de la persistencia, sino el límite mental a partir del cual se desaferra como carácter de además en ascenso metódico noético solidario con el núcleo de sentido luminoso. Por eso, afirma Polo que el carácter de además es más distinto de Dios que de la nada ${ }^{77}$, en tanto que sentido personal creado que busca su tema el Sentido Originario, por el que fue creado ad-extra ${ }^{78}$. El tema del co-sentido en tanto que búsqueda es el Sentido como Origen y Destino del sentido personal, pero en total dependencia, no al modo de la persistencia en tensión con la nada, sino como luz radical creada en semejanza trascendental a su tema, es decir, como apertura de co-luz libre cognoscente, orientada constitutivamente al encuentro de sentido personal con su Origen.

El co-sentido como además es, por tanto, adverbio que busca al Verbo como tema en tanto que Luz Originaria superior a la cual destinarse, por ser luz de co-sentido como su imagen semejante en dependencia de la Luz del Sentido Originario. La semejanza radica en ser sentido personal, aunque creatural, por no ser sentido idéntico, sino como transparencia intensa de luz en la luz, abierta a otra Luz en el encuentro entre ámbitos luminosos desiguales. Es decir, como sentido creado ante el Sen-

77. A pie de página Polo aclara: "Dios "se ocupa" de la nada para crear: crea "fijándose en "la nada para establecer una distinción superior, es decir, la de la creatura con Dios. La consideración filosófica de la nada se reduce a esto. Nada es la exclusión completa de que la criatura se distinga más de cualquier otra instancia que de Dios. Dios no crearía si lo creado se distinguiera más de cualquier otra cosa que de Él”. Polo, L., Antropología, I, 136. También en otra nota dice: "La nada se describe se describe como la contramedida del ser creado: la criatura superior es la que más se distingue de Dios y, por consiguiente, la que menos se distingue de la nada, es decir, la que menos tiene que ver con ella”. Polo, L., Antropología, I, 142.

78. "Como la criatura se distingue del ser Originario, no solo se dice que es extra nihilum, sino también que Dios la crea ad extra [...] Por decirlo de alguna manera: Dios 'se ocupa' de la nada exclusivamente en atención a la creatura; es decir, la crea excluyendo la nada de ella y, por tanto, distinguiéndola de la nada. Por tanto, la creación hunde sus raíces en el misterio del amor divino. Crear al ser inferior sin más al Ser Originario es una distinción simplemente admirable, y en modo alguno una diferencia”. Polo, L., Antropología, I, 135.

Thémata. Revista de Filosofía $\mathrm{N}^{\circ} 56$ (2017) pp.: 255-284. 
tido Originario que es "Luz eternamente generada por la Luz", y que como Origen es "Luz en cuyo seno se genera la Luz". Escribe Polo:

\begin{abstract}
Dios es el Verbo y el hombre el adverbio. Dicho adverbio es el carácter de además, cuya exposición ha llevado a alcanzar el intelecto personal humano como transparencia intensa, es decir, luz cuyo interior es luz. Según esto, el adverbio es semejante al Verbo. El hombre es imagen de Dios. En el Credo Niceno se describe al Hijo como lumen de lumine, es decir, como Luz eternamente generada por la Luz. El Origen es Luz en cuyo seno se genera la Luz. Ahora bien, como el hombre es creado, para alcanzar la intensidad de la transparencia, es menester la dualidad solidaria del hábito de sabiduría con el intelecto personal. En otro caso, habría que sostener que la co-existencia comporta dos personas, pero ello es claramente inadmisible. En la persona creada la luz que penetra la luz no es generada, sino creada ${ }^{79}$.
\end{abstract}

Por tanto, el co-sentido creatural es semejante como imagen creada no idéntica en cuanto requiere la dualidad solidaria con la sabiduría desde su transparencia para abrirse como ámbito íntimo luminoso que se trueca en búsqueda aceptante de su tema. El co-sentido como co-luz no se refiere a dos personas o dos sentidos, pues la luz penetrante en la luz es creatural, no originaria por dentro, es decir, el co-sentido es creado por el Sentido Originario como co-luz dual solidaria íntima que requiere alcanzarse por no ser idéntica. Esa co-luz se trueca en búsqueda-aceptante, es decir, en transparencia intensa luminosa dual que se destina a Luz Superior que en cuanto búsqueda orientada es ya atravesada por su tema. La búsqueda como destinación al encuentro de esplendor de Sentido personal no es, por tanto, un proceso, sino el co-sentido como búsqueda aceptante, un buscar que es ya inclusión íntima en el Sentido Originario; y, en tanto que aceptación de la creatura, es ya donal de la propia luz como ofrecimiento a su tema.

De otro modo, el co-sentido volcado hacia adentro como búsqueda-aceptante indica que, a su vez, es alcanzado por el tema, que en tanto que superior, es inclusión en la interioridad de resplandor abierta como ámbito de máxima amplitud. El tema trasciende el co-sentido sin confundirse con él, es decir, sin obnubilarlo, porque le dona su Luz a un sentido distinto de él, al co-sentido creatural, en relación íntima de sentido personal que al atravesarlo lo performa, es decir, lo transforma activamente con su Luz dentro de la luz que se le destina haciéndolo quién está llamado a ser en plenitud de su co-ser de sentido luminoso.

Con otras palabras, el co-sentido es conversión luminosa dual como intimidad y como búsqueda-aceptante de su tema. El co-sentido como intimidad es intensidad de luz transparente que se dualiza en actividad libre.

79. Ibid., 197-198.

Thémata. Revista de Filosofía $\mathrm{N}^{\circ} 56$ (2017) pp.: 255-284. 
El co-sentido como búsqueda aceptante es acto de ser luminoso dualizado en intelecto aceptante donal. La luz libre ${ }^{80}$ del co-sentido como transparencia se dualiza con la búsqueda aceptante del Sentido superior como réplica. La búsqueda es aceptación de la Luz Originaria en encuentro donal esplendoroso de ofrecimiento ${ }^{81}$. Cuanto mayor es la luminosidad de la dualidad trascendental mayor la riqueza de su conversión de co-sentido transparente libre como búsqueda aceptante donal. Sin el encuentro esplendoroso de sentidos, el co-sentido creatural no se descubriría como luz incluida en la Luz, es decir, como verdad en la Verdad. De aquí la riqueza de la dualidad de luz íntima como búsqueda aceptante que en el encuentro con el Sentido Originario es ofrecimiento donal de la propia co-luz para el reconocimiento de su propia verdad como sentido personal.

Por tanto, alcanzar el co-sentido es conocerse sin término como persona ${ }^{82}$, es decir, como apertura luminosa de co-luz que busca su tema aceptándolo. De aquí el conocimiento solidario que el además alcanza del carácter dinámico de sus radicales en conversión trascendental, abierto a

80. "El vínculo de la persona humana con Dios es nativo, pero es libre. La libertad personal es apertura, es para; por tanto, requiere de una aceptación personal, de un destinatario. Esto indica que una libertad personal en solitario es absurda o, lo que es lo mismo, imposible. Por eso las descripciones modernas y contemporáneas de la libertad como "espontaneidad", "autonomía", "independencia", etc. son, para Polo, reductivas. Por su parte, las descripciones clásicas de la libertad como "dominio de nuestros actos", "capacidad de elección", etc., las cuales ciñen en exclusiva la libertad a las manifestaciones humanas, son asimismo reductivas. Lo que precede significa que no se trata de que la persona tenga libertad, sino de que es libertad. Cada persona es una libertad distinta e irreductible a las demás. La persona es libertad. Como se ha adelantado, la noción de persona y la realidad que bajo ella subyace ha sido históricamente un descubrimiento cristiano y, en consecuencia, netamente teológico. Pero también es un tema filosófico, antropológico, el cual tiene, desde luego, relevantes implicaciones para la teología natural." SELLÉS, J.F., "La teología natural según Leonardo Polo" Revista de humanidades Santiago, [Chile] 28 (2013) 64.

81. "La cuestión del destinar comporta que la actividad del hombre rebrota en dación desde la persona. El destinar no se confunde con el destino. Por decirlo de algún modo, al hacer el balance de su vida desde su ser personal, el hombre se encuentra con que no le basta un término último de su capacidad de desear, sino que ha de buscar el término de su capacidad de ofrecimiento". Polo, L., "La esperanza", Scripta Theologica, 30/1 (1998) 163.

82. En contraste con el sentido del acto de ser humano que se alcanza, así enmarca Polo la pregunta por el sentido personal en nuestra altura histórica: "nuestra época se encuentra en un nivel sapiencial y de autocomprensión mítico... Basta caer en cuenta de la gran duda que el hombre tiene acerca de su destinación en nuestra situación cultural. ¿A dónde vamos? A una situación espectral, a una situación de volatilización... ¿Qué destino tenemos? Un destino negativo. ¿Cómo nos enfrentamos con el futuro?; ¿qué hacer con el futuro? Nada. ¿Cuál es el sentido de nuestra existencia actual? Muy escaso. Pensiero debole”. Polo, L., Presente y futuro del hombre, cit., 34 .

Thémata. Revista de Filosofía №56 (2017) pp.: 255-284. 
más luz en aceptación libre cognoscente para el ofrecimiento de la propia co-luz a su tema.

En resumen, la criatura humana es puro sobrar de co-sentido en sus distintos ámbitos de ser y esencia; sobrar de co-sentido que no abandona su manifestación potencial como tampoco se cierra al universo que habita manifestado con sus leyes en su propia corporeidad, sino que la co-luz metódico-temática del co-sentido radical es ámbito interior de apertura coexistente-cognoscente, que como su luz trascendente superior es generosamente otorgada a los hábitos innatos según sus temas y en distinción de sentidos manifestativos donales para hacerse cargo de su esencia y del cosmos. El co-sentido personal es alguien que, por ser co-sentido creatural o co-luz, de orienta a su tema Originario a la vez que se hace cargo del algo esencial que depende de sí dotándolo de sentido trascendental en descenso de nivel de carácter donal, para advertir otro acto de ser, así como para estrecharse su esencia dotándola de su sentido para acrecentarla.

La dualidad de luz en el abandono del límite del carácter de además por el hábito de sabiduría, así como la vuelta de co-luz de sentido a la esencia por la sindéresis, marca la distinción entre el co-sentido como acto de ser capaz de ofrecimiento y la dotación de sentido a su esencia, en tanto que modos dispositivos de otorgamiento de su co-luz en sentidos donales como manifestación. Es también la distinción entre el co-sentido trascendental orientado al Sentido Originario orientado a su Destino y los sentidos donales de la coexistencia esencial abiertos a los otros sentidos creaturales y al cosmos. Polo escribe sobre el sentido personal como ofrecimiento:

Si el sentido de mi vida no se agota en la felicidad, según la acepción griega, es decir, en una posesión perfecta, sino que mi actividad rebrota en dación desde la persona, el destinar no se confunde con el destino. La cuestión del destinar reside en el destinatario. Por decirlo de algún modo, al hacer el balance de todo lo que es desde la persona, el hombre se encuentra con que eso no le basta, sino que tiene que encontrar un término, que no es el término del deseo, sino el del ofrecimiento. ${ }^{83}$

\section{Conclusiones}

El carácter de además es co-luz métodico-temática que alcanza el sentido personal, por tanto, co-sentido. A la par que el método es además

83. Polo, L., Sobre la existencia cristiana, cit., 133.

Thémata. Revista de Filosofía $\mathrm{N}^{\circ} 56$ (2017) pp.: 255-284. 
luminoso que alcanza su tema de co-sentido, también se alcanza la antropología en distinción de la metafísica.

Tanto la dualidad radical de co-luz del ser personal como el ser del universo, así como la dualidad de la cima de la esencia personal y la esencia extramental, se conocen con el abandono del límite mental en las distintas dimensiones de conocimiento propuestas por Polo, según el tema a conocer.

El sentido personal es co-luz íntima otorgante unitiva por su atravesar temático de todos los niveles de la estructura humana, desde su transparencia íntima abierta en ascenso al Sentido Originario, y en descenso a todo lo inferior; es decir, por destinarse el co-sentido como búsqueda aceptante de Luz Originaria, en tanto que apertura interior luminosa y libre, la co-luz íntima insiste en ser dinamismo luminoso de sentido, como además que va a más. Por tanto, este ámbito íntimo de amplitud luminosa se ensancha de modo otorgante, para traspasar con su luz los hábitos innatos y la esencia, incluso hasta la sensibilidad externa, en una desintensificación de luz trascendental. De aquí el carácter otorgante de luz unitiva del co-sentido personal.

El sentido personal es acto de ser que, en tanto que co-luz, es un ámbito íntimo abierto, libre, cognoscente como búsqueda aceptante amoroso-donal. La co-luz del sentido personal o co-sentido es solidaridad de luz como método de además que abandona el límite mental al alcance de la co-luz íntima transparente como tema. Este ámbito no es inmanente, sino intimidad personal de luz en la luz de nivel trascendental; por ello, el co-sentido es núcleo o acto de ser personal, que se alcanza como antropología con la ampliación trascendental en la tercera dimensión del abandono del límite mental.

Por ser co-luz íntima, el co-sentido es ámbito de amplitud interior activo y cognoscente trocado en búsqueda-aceptante de su tema. El tema del co-sentido, por tanto, debe ser Sentido personal Originario que como origen es Luz; en consecuencia, capaz de ser réplica para la co-luz creatural que lo busca. El Sentido Originario es intimidad personal, descrita por Polo como ámbito interior de máxima amplitud, capaz de acoger la co-luz creada en un encuentro personal singular de la co-luz con la Luz; por tanto, en un encuentro de esplendor de sentidos personales que atraviesa a la criatura desde el Sentido originario como Trascendens, sin obnubilarlo sino performándolo, es decir, acrecentándolo y restaurándolo. Por eso el sentido personal es co-luz íntima que busca el Sentido Originario.

Thémata. Revista de Filosofía Nº56 (2017) pp.: 255-284. 
María Victoria Cadavid Claussen

Thémata. Revista de Filosofía N56 (2017) pp.: 255-284. 